\title{
CONTRIBUIÇÃO AO ENTENDIMENTO DA SENSIBILIDADE AMBIENTAL AO DERRAMAMENTO DE ÓLEO NO LITORAL DE MARICÁ NO ESTADO DO RIO DE JANEIRO
}

\section{Contribution of understanding of environmental sensitivity of the oil spill in Maricá coastline of Rio de Janeiro State}

\author{
Érika Cardoso da Silva Baptista \\ Mestranda do Programa de Pós-Graduação em Geografia na FFP-UERJ \\ erikacardosogeo@gmail.com \\ André Luiz Carvalho da Silva \\ Professor Adjunto do Departamento de Geografia - UERJ/FFP \\ andrelcsilvageouerj@gmail.com
}

Carolina Pereira Silvestre Doutoranda em Dinâmica dos Oceanos e da Terra do Departamento de Geologia - UFF cps_silvestre@hotmail.com

Artigo recebido em 15/10/2015 e aceito para publicação em 28/10/2015

DOI: 10.12957/tamoios.2015.19191

Resumo

Abstract

Desastres associados ao transporte marinho e terrestre de hidrocarbonetos causam sérios impactos aos ambientes costeiros, afetando a fauna e a flora marinha, além de prejudicar diversas atividades econômicas, inclusive àquelas tradicionais, como é o caso da pesca artesanal. Assim, faz-se necessário conhecer a geologia e a geomorfologia da costa, em especial as praias devido à elevada dinâmica e vulnerabilidade desses ambientes. A construção de megaempreendimentos na zona costeira e o tráfego de navios petroleiros e pequenas embarcações, ou mesmo a implantação de dutos, localizados junto à linha de costa, representam uma ameaça ao equilíbrio dos ecossistemas. Para tal, foram analisados diversos aspectos da geomorfologia costeira de Maricá, para posterior identificação do grau de sensibilidade deste litoral a eventos de derramamento de óleo, a partir do Índice de Sensibilidade Ambiental (ISA) proposto pelo Ministério do Meio Ambiente. O litoral de Maricá, ao longo de $34 \mathrm{~km}$ de extensão entre Itaipuaçú (no extremo oeste) e Ponta Negra (a leste), apresenta quatro áreas distintas quanto à sensibilidade à poluição decorrente de derramamento de óleo, sendo: ISA1, para as áreas de costões rochosos localizados nas extremidades leste e oeste deste litoral; ISA4, para a quase totalidade das praias, formadas por areias quartzosas grossa e média, exceto o extremo-oeste de Itaipuaçú, que possui areia muito grossa e cascalhos sendo, portanto, representada pelo ISA5; e ISA10, para as lagoas costeiras e canais na retaguarda das barreiras arenosas, sujeitas à contaminação por meio dos canais e por transposição por grandes ondas de tempestades. Os índices compreendem os extremos dessa classificação, devido à grande variedade de elementos na paisagem costeira de Maricá e mostra a elevada sensibilidade deste litoral, frente à ameaça de desastres causados por derramamento de óleo.

Palavras-chave: poluição; hidrocarbonetos; ISA; Maricá.

Disasters associated with marine transportation and hydrocarbon terrestrial cause serious impacts on coastal environments, affecting the fauna and marine flora, and undermine various economic activities, including those traditional, as is the case of artisanal fisheries. Thus, it is necessary to know the geology and geomorphology of the coast, especially the beaches due to high dynamics and vulnerability of these environments. The construction of mega-projects in the coastal zone and the traffic of oil tankers and smaller vessels, or even deploying ducts, located next to the coastline, pose a threat to the equilibrium of ecosystems. To this end, various aspects of coastal geomorphology of Maricá were analyzed for further identification of the degree of sensitivity of the coastline to oil spill events from the Environmental Sensitivity Index (ESI) proposed by the Ministry of Environment. The coastline of Maricá, over $34 \mathrm{~km}$ long between Itaipuaçú (at the west end) and Ponta Negra (east), presents four distinct areas for sensitivity to pollution from oil spills, as follows: ESI1 for the areas of rocky shores located on the east and west ends of this coast; ESI4, for almost all the beaches, formed by thick quartz sands and medium except the extreme west of Itaipuaçú, which has very coarse sand and gravel is thus represented by ESI5; and ESI10 for the coastal lagoons and channels in the rear of sand barriers, subject to contamination through the channels and transposition by large waves of storms. The indexes include the extreme of this classification due to the wide variety of elements in the coastal landscape of Maricá and shows the high sensitivity of this coast, facing the threat of disasters caused by oil spills.

Keywords: pollution; hydrocarbons; ESI; Maricá. 


\section{INTRODUÇÃO}

Os ambientes costeiros são essencialmente dinâmicos e apresentam uma capacidade de regeneração em resposta a desastres ambientais que pode variar bastante de acordo com o tipo, intensidade e forma de ocorrência de um evento qualquer. A recuperação de um ambiente afetado por um derramamento de óleo, por exemplo, pode ser rápida ou extremamente lenta, dependendo das características morfológicas e sedimentares de cada seguimento do litoral (MMA, 2004). Além disso, a variabilidade nas condições de mar, com a alternância entre períodos de tempo bom e tempestades eventuais, produz variações temporais na sensibilidade dos diversos ambientes costeiros (FINGAS, 2000).

O trecho escolhido para a realização deste estudo compreende o município de Maricá (Fig. 1), que está localizado no Estado do Rio de Janeiro, entre Niterói (a oeste) e Saquarema (a leste). Com um total de $34 \mathrm{~km}$ de extensão, a área de estudo compreende os litorais de Itaipuaçú, APA e Barra de Maricá, Guaratiba, Cordeirinho e Ponta Negra, distribuídas de oeste para leste, respectivamente (Fig. 1). Este trabalho objetiva analisar a sensibilidade ambiental do litoral de Maricá frente à ocorrência de desastres associados a derramamento de óleo, considerando-se as principais características geológicas deste trecho do litoral fluminense. Para tal, foi necessário considerar: a geomorfologia e a sedimentologia dos ambientes deposicionais costeiros, os condicionantes oceanográficos e a vulnerabilidade deste litoral aos eventos de tempestades e, por fim, realizar um mapeamento costeiro baseado no índice de sensibilidade ambiental do litoral a derramamento de óleo.

O número de acidentes com derramamento de óleo, tanto em ambientes costeiros como marinhos, tem aumentado nos últimos anos no Brasil e no mundo (Tab.1; Fig. 2). O aumento na utilização de petróleo e, consequentemente, da circulação de grandes navios e embarcações de pequeno e médio porte são os principais responsáveis pelo despejo de óleo e derivados no oceano, que pode ocorrer acidentalmente e por lavagem de navios tanques (SKINNER \& TUREKIAN, 1977; BOULHOSA \& SOUZA FILHO, 2009; MENEGHETTI et al., 2011). A destruição de habitats costeiros, a intoxicação e asfixia de animais marinhos e aves migratórias estão entre os principais impactos ambientais. Os impactos na economia das áreas afetadas consistem principalmente na diminuição da atividade pesqueira e no comprometimento das atividades de lazer, 
afetando diretamente o turismo. Para que sejam reconhecidos e diferenciados os graus de impactos causados por derramamento de óleo no litoral, foi definido o Índice de Sensibilidade Ambiental (ISA). O ISA é adotado pela Organização Marítima Internacional (IMO), pela Administração Atmosférica e Oceânica Nacional (NOAA) dos Estados Unidos; no Brasil, pelo Centro de Pesquisa e Desenvolvimento da PETROBRAS (CENPES), pelo Ministério do Meio Ambiente (MMA) e em diversas pesquisas voltadas para a preservação ambiental dos litorais frente aos impactos causados por derramamentos de óleo (BOULHOSA \& SOUZA FILHO, 2009; CASTRO et al., 2003; MENEGHETTI et al., 2011; ROCHA, 2009; ROMERO, 2009, entre outras).

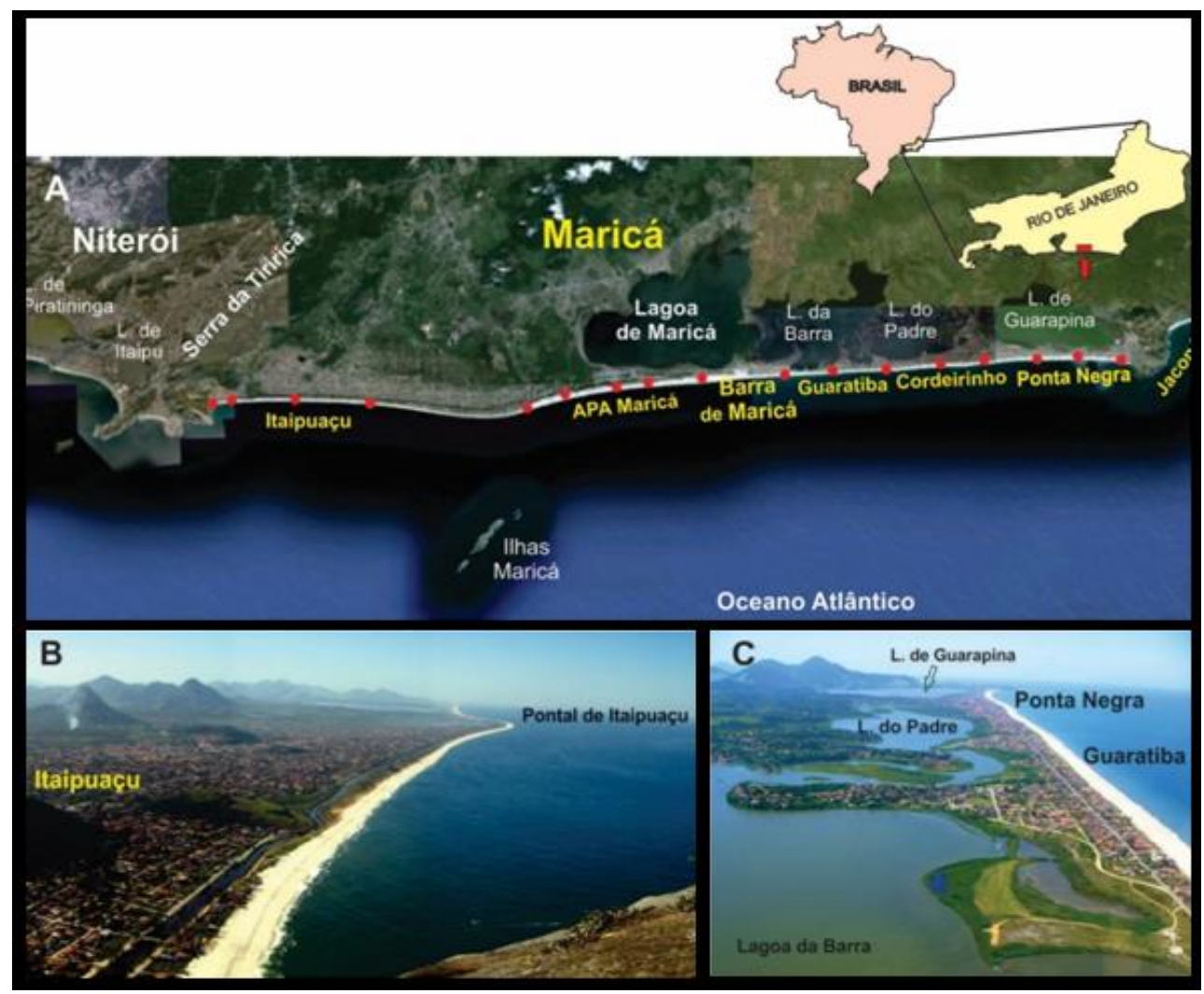

Figura 1- (A) Litoral de Maricá, com a indicação dos locais de monitoramento; (B, C) Geomorfologia do litoral de Maricá: praias e lagoas à retaguarda das barreiras. Fonte: A, Imagem do Google Earth, 2009; B, André Silva (2004); C, Desirée Guichard, 2009.

\section{ÁREA DE ESTUDO}

A geomorfologia do litoral de Maricá é caracterizada pela presença de duas barreiras arenosas (Fig. 1), uma mais interna formada no Pleistoceno e outra mais externa de idade holocênica, separadas por uma série de lagunas colmatadas (SILVA, 2011; SILVA et al., 2014a; SILVA et al., 2014b; SILVA et al., 2014c). Um sistema lagunar 
formou-se nesta planície costeira na retaguarda da barreira pleistocênica, representado pelas lagoas de Maricá, Barra, Padre e Guarapina, sendo esta última conectada ao mar por um canal artificial. A dinâmica costeira de Maricá é determinada principalmente pela incidência de ondas de alta energia associada à formação de correntes responsáveis por amplas variações na largura e morfologia das praias (MUEHE, 1979; GRALATO, 2013; SILVA, 2006; SILVA et al., 2008a; SILVA et al., 2014c, FERREIRA, 2014; SILVA et al., 2015). A variação da maré neste litoral não ultrapassa 1,5 metro (DHN, 1980). A incidência de ondas é predominantemente de SE em condições de tempo bom, contribuindo para a formação de correntes de deriva litorânea preferencialmente em direção a oeste. Grandes ondas de tempestades predominam de S e SW (MUEHE, 1979; SILVA, 2006; SILVA et al., 2008a).

Tabela 1 - Principais eventos de derramamento de óleo no Brasil e no mundo, ocorridos entre os anos de 1978 e 2015.

\begin{tabular}{|c|c|c|c|c|}
\hline Data & Local & Volume & Impactos & Fonte \\
\hline 2015 & $\begin{array}{l}\text { Mangaratiba/ } \\
\text { Rio de Janeiro }\end{array}$ & 30 mil litros & A contaminação atingiu áreas de manguezal e o mar. & Mendes $(2015)^{1}$ \\
\hline 2000 & $\begin{array}{l}\text { Baía de Guanabara/ } \\
\text { Rio de Janeiro }\end{array}$ & $\begin{array}{l}\text { 1,3 milhão } \\
\text { de litros }\end{array}$ & $\begin{array}{l}\text { Contaminação dos manguezais, elevada mortandade de } \\
\text { peixes, impacto direto nas atividades pesqueiras. }\end{array}$ & Ortiz $(2014)^{2}$ \\
\hline 2000 & Araucária/ Paraná & $\begin{array}{l}4 \text { milhões de } \\
\text { litros }\end{array}$ & $\begin{array}{l}\text { Afetou diretamente a flora local e a vida marinha, além } \\
\text { dos danos causados à população ribeirinha. }\end{array}$ & Magnabosco $(2013)^{\mathbf{3}}$ \\
\hline 2004 & $\begin{array}{l}\text { Porto de Paranaguál } \\
\text { Paraná }\end{array}$ & $\begin{array}{l}4 \text { milhões de } \\
\text { litros }\end{array}$ & $\begin{array}{l}\text { Ocasionou a morte de muitas espécies da fauna marinha } \\
\text { local. }\end{array}$ & Galindo $(2005)^{4}$ \\
\hline 1994 & $\begin{array}{l}\text { São Sebastião/ } \\
\text { São Paulo }\end{array}$ & $\begin{array}{l}2,7 \text { milhões } \\
\text { de litros }\end{array}$ & $\begin{array}{l}\text { A contaminação atingiu o subsolo, cursos d'água e } \\
\text { lençóis freáticos. }\end{array}$ & Rodrigues $(2012)^{\mathbf{5}}$ \\
\hline 1991 & Itália & $\begin{array}{l}144 \text { mil } \\
\text { toneladas }\end{array}$ & $\begin{array}{l}\text { A poluição se estendeu pelos } 12 \text { anos seguintes na costa } \\
\text { mediterrânea da Itália e da França. }\end{array}$ & Barbosa $(2013)^{6}$ \\
\hline 1991 & Angola & $\begin{array}{c}260 \text { mil } \\
\text { toneladas }\end{array}$ & $\begin{array}{l}\text { Milhões de litros de petróleo vazaram para o Oceano } \\
\text { Atlântico, afetando a vida marinha. }\end{array}$ & Barbosa $(2013)^{6}$ \\
\hline 1983 & África do Sul & $\begin{array}{l}252 \text { mil } \\
\text { toneladas }\end{array}$ & $\begin{array}{l}\text { O vento forte evitou que a mancha alcançasse o litoral, } \\
\text { minimizando os efeitos do desastre. }\end{array}$ & Barbosa $(2013)^{6}$ \\
\hline 1979 & $\begin{array}{c}\text { Baía do Campeche/ } \\
\text { Golfo do México }\end{array}$ & $\begin{array}{l}454 \text { mil } \\
\text { toneladas }\end{array}$ & $\begin{array}{l}\text { Uma enorme mancha de óleo atingiu mais de } 1600 \mathrm{~km}^{2} \\
\text { de litoral, afetando os ecossistemas marinhos. }\end{array}$ & Barbosa $(2013)^{6}$ \\
\hline 1978 & França & $\begin{array}{l}223 \text { mil } \\
\text { toneladas }\end{array}$ & $\begin{array}{l}\mathrm{O} \text { vazamento matou milhares de animais e aves } \\
\text { marinhas, que ficaram cobertas de petróleo. }\end{array}$ & Barbosa $(2013)^{6}$ \\
\hline
\end{tabular}

${ }^{1}$ http://noticias.band.uol.com.br/cidades/rio/noticia/100000757576/Derramamento-de-oleo-atinge-RioItingucu-e-Baia-de-Sepetiba.html

2 http://www.oeco.org.br/reportagens/28021-baia-de-guanabara-vazamento-da-petrobras-completa-14anos/ parana, 1064446

http://economia.estadao.com.br/noticias/geral,petrobras-pagara-r-610-mi-por-vazamento-no-

${ }^{4} \mathrm{http} / / /$ noticias.ambientebrasil.com.br/clipping/2005/11/15/21716-explosao-do-navio-vicua-no-porto-deparanaguapr-ainda-sem-culpados.html

5 http://g1.globo.com/sp/vale-do-paraiba-regiao/noticia/2012/09/secretario-fala-sobre-vazamento-deoleo-diesel-em-sao-sebastiao.html

${ }^{6}$ http://exame.abril.com.br/mundo/noticias/10-maiores-acidentes-petroliferos-historia-556774

Na porção central da área de estudo encontra-se localizada a Área de Proteção Ambiental de Maricá (Fig. 1), que apresenta uma rica biodiversidade, com cerca de 408 espécies de flora e fauna endêmicas e ameaçadas de extinção, sítios arqueológicos e alguns recursos minerais (FARIA \& BOHRER, 2005; LOUREIRO et al., 2010). Este 
litoral vem experimentando um rápido crescimento populacional nas últimas décadas. Um grande empreendimento ligado à indústria do petróleo está sendo instalado na região (COMPERJ). A construção do COMPERJ prevê a instalação de um duto no litoral de Itaipuaçú para eliminar resíduos produzidos na refinaria, de um gasoduto para receber o gás natural extraído na Bacia de Santos e de um porto em Jaconé (limite leste da área de estudo) para atender a recente demanda criada por esse complexo petroquímico. Soma-se a essas ameaças o crescimento do tráfego marítimo de navios petroleiros na região, que aumenta o risco de desastres causados por derramamento de óleo e compromete o equilíbrio dos ecossistemas marinhos e costeiros.

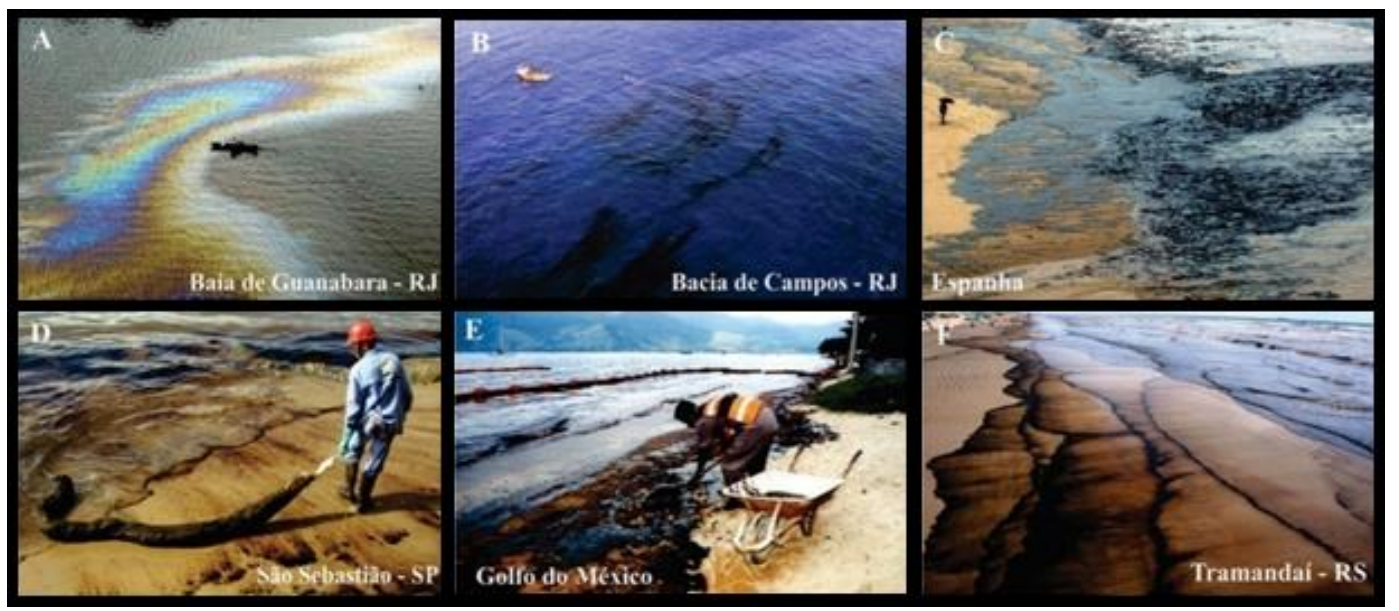

Figura 2- Alguns exemplos de desastres ambientais causados por derramamentos de óleo em litorais no Brasil e no mundo. Fonte: A, Custódio Coimbra (2005); B, Aloar Filho (2001); C, Carmelo Alen (2002); D, Reginaldo Pupo (2013); E, Autor desconhecido; F, Pedro Revillion (2012).

\section{METODOLOGIA}

A morfologia, sedimentologia e condições de mar da área estudada foram obtidos a partir de dados adquiridos em estudos realizados anteriormente por Silva et al. (2008a; 2008b) para Itaipuaçú; Gralato (2013) e Silva et al. (2014c) para a área da APA de Maricá; Ferreira (2014) e Silva et al. (2015) no trecho que corresponde às praias de Barra de Maricá, Guaratiba, Cordeirinho e Ponta Negra. Esses dados resultam de uma pesquisa voltada para o conhecimento da dinâmica das praias de Maricá, por meio da aquisição de perfis topográficos de praia entre as estações do ano, com concomitante análise textural dos sedimentos, ao longo de 17 pontos de monitoramento (Fig. 1A) distribuídos em 34 quilômetros de litoral.

A integração desses dados permitiu a caracterização da geologia e dos ambientes deposicionais costeiros (praias, lagoas, etc.), tornando possível a confecção do Mapa de 
Sensibilidade Ambiental do litoral de Maricá a desastres causados por derramamento de óleo, seguindo a classificação proposta pelo Ministério do Meio Ambiente (2004) (Tab. 2). Para tal, foi utilizado o programa ArcGis 9.3, com imagens do satélite Landsat 8. Os principais elementos geomorfológicos foram mapeados por meio da geração de polígonos e linhas para a representação do ISA. O Índice de Sensibilidade Ambiental (ISA) varia numa escala de 1 a 10 , sendo 1 para os ambientes menos sensíveis e 10 para os mais sensíveis ao derramamento de óleo. Nessa classificação são consideradas as características geológicas e geomorfológicas do litoral, a partir da exposição à energia de ondas e marés, declividade e tipo de substrato, que são fundamentais para a determinação do grau do impacto; o tempo de permanência e o comportamento do óleo derramado; e o transporte de sedimentos (CASTRO et al., 2003; ROCHA, 2009; ROMERO, 2009; MMA, 2004).

\section{RESULTADOS E DISCUSSÃO}

\section{Caracterização geológica e sedimentar do litoral de Maricá}

O litoral de Maricá (Fig. 1 e 3) apresenta uma geologia marcada pela presença de costões rochosos formados basicamente por granitos e gnaisses de idade PréCambriana (DRM, 1977) e uma geomorfologia de barreiras arenosas associadas a sistemas lagunares (SILVA et al., 2014c). As praias são dinâmicas e apresentam características distintas do ponto de vista morfológico e sedimentar em resposta à exposição às ondas e às variações nas condições de mar ao longo do litoral (MUEHE, 1979; SILVA et al., 2008a; GRALATO, 2013; SILVA et al., 2014c; FERREIRA, 2014; SILVA et al., 2015).

\section{Costões rochosos}

As formações rochosas ao longo do litoral de Maricá são afloramentos de maciços costeiros, representados pelos costões de Itaipuaçú (Fig. 3A) e de Ponta Negra (Fig. 3B), situados nos extremos oeste e leste do arco praial, respectivamente (SILVA et $a l ., 2014 c)$. Essas áreas são caracterizadas por uma exposição direta à incidência de ondas com altura geralmente superior a 1 metro e que podem alcançar mais de 3 metros durante a ocorrência de ressacas (SILVA et al., 2008a). Esses costões (Fig. 3A e 3B) apresentam elevada declividade, o que proporciona a reflexão das ondas incidentes e impede a concentração de óleo. A superfície destas rochas é predominantemente lisa e 
sem grandes rugosidades, o que contribui para sua baixa permeabilidade. $\mathrm{O}$ alcance máximo das ondas de tempestades sobre os costões é facilmente observado devido à diferença de cor na superfície das rochas, que apresentam uma cor mais clara em relação às áreas acima, e ausência de vegetação.

Tabela 2 - Classificação do Índice de Sensibilidade Ambiental proposto pelo Ministério do Meio Ambiente (MMA, 2004).

\begin{tabular}{|c|c|c|c|c|c|}
\hline \multirow[t]{2}{*}{ COR } & \multirow[t]{2}{*}{ ÍNDICE } & \multicolumn{3}{|c|}{ CÓDIGO } & \multirow[t]{2}{*}{ TIPOS DE COSTA } \\
\hline & & $\mathbf{R}$ & G & B & \\
\hline & ISL 1 & 119 & 38 & 105 & $\begin{array}{l}\text { - Costōes rochosos lisos, de alta declividade, expostos } \\
\text { - Falésias em rochas sedimentares, expostas } \\
\text { - Estruturas artificiais lisas (paredōes maritimos artificiais), expostas }\end{array}$ \\
\hline & ISL 2 & 174 & 153 & 191 & $\begin{array}{l}\text { - Costōes rochosos lisos, de declividade média a baixa, expostos } \\
\text { - Terraços ou substratos de declividade média, expostos (terraço ou } \\
\text { plataforma de abrasão, terraço arenítico exumado bem consolidado, } \\
\text { etc.) }\end{array}$ \\
\hline & ISL 3 & 0 & 151 & 212 & $\begin{array}{l}\text { - Praias dissipativas de areia média a fina, expostas } \\
\text { - Faixas arenosas contíguas à praia, nāo vegetadas, sujeitas à açāo de } \\
\text { ressacas (restingas isoladas ou múltiplas, feixes alongados de restingas } \\
\text { tipo \%ong beach") } \\
\text { - Escarpas e taludes íngremes (formaçōes do grupo Barreiras e } \\
\text { Tabuleiros Litorâneos), expostos } \\
\text { - Campos de dunas expostas }\end{array}$ \\
\hline & ISL 4 & 146 & 209 & 241 & $\begin{array}{l}\text { - Praias de areia grossa } \\
\text { - Praias intermediárias de areia fina a média, expostas } \\
\text { - Praias de areia fina a média, abrigadas }\end{array}$ \\
\hline & ISL 5 & 152 & 206 & 201 & $\begin{array}{l}\text { - Praias mistas de areia e cascalho, ou conchas e fragmentos de corais } \\
\text { - Terraço ou plataforma de abrasão de superficie irregular ou recoberta } \\
\text { de vegetação } \\
\text { - Recifes areníticos em franja }\end{array}$ \\
\hline & ISL 6 & 0 & 149 & 32 & $\begin{array}{l}\text { - Praias de cascalho (seixos e calhaus) } \\
\text { - Costa de detritos calcários } \\
\text { - Depósito de tálus } \\
\text { - Enrocamentos ("rip-rap", guia corrente, quebra-mar) expostos } \\
\text { - Plataforma ou terraco exumado recoberto por concreçōes lateríticas } \\
\text { (disformes e porosas) }\end{array}$ \\
\hline & ISL 7 & 214 & 186 & 0 & $\begin{array}{l}\text { Planície de maré arenosa exposta } \\
\text { - Terraço de baixa-mar }\end{array}$ \\
\hline & ISL 8 & 225 & 232 & 0 & $\begin{array}{l}\text { - Escarpa / encosta de rocha lisa, abrigada } \\
\text { - Escarpa / encosta de rocha nāo lisa, abrigada } \\
\text { - Escarpas e taludes íngremes de areia, abrigados } \\
\text { - Enrocamentos ("nip-rap" e outras estruturas artificiais não lisas) } \\
\text { abrigados }\end{array}$ \\
\hline & ISL 9 & 248 & 163 & 0 & $\begin{array}{l}\text { - Planície de maré arenosa / lamosa abrigada e outras áreas úmidas } \\
\text { costeiras não vegetadas } \\
\text { - Terraço de baixa-mar lamoso abrigado } \\
\text { - Recifes areníticos servindo de suporte para colônias de corais }\end{array}$ \\
\hline & ISL 10 & 214 & 0 & 24 & $\begin{array}{l}\text { - Deltas e barras de rio vegetadas } \\
\text { - Terraços alagadiços, banhados, brejos, margens de rios e lagoas } \\
\text { - Brejo salobro ou de água salgada, com vegetaçāo adaptada ao meio } \\
\text { salobro ou salgado; apicum } \\
\text { - Marismas } \\
\text { - Manquezal (manques frontais e mangues de estuários) }\end{array}$ \\
\hline
\end{tabular}

\section{Praias}

No litoral de Maricá, as praias são dinâmicas e apresentam um perfil geralmente íngreme em resposta à exposição direta à incidência de grandes ondas de tempestades. Essas praias apresentam grandes variações na morfologia e na largura, com destaque para a praia de Itaipuaçú, que é a mais dinâmica e mais vulnerável às ressacas (Fig. 3C) 
e ao fenômeno de transposição de ondas (SILVA et al., 2008a; SILVA et al., 2014c). Durante as tempestades de grande magnitude, as ondas eventualmente ultrapassam o limite interno da praia e transpõem a barreira arenosa formando depósitos de leques de arrombamento (SILVA et al., 2008b). Correntes de deriva litorânea parecem predominar para oeste neste litoral, em resposta à incidência predominante de ondas de SE; correntes de retorno são vigorosas e em geral associadas à incidência de ondas de $\mathrm{S}$ (SILVA et al., 2008a; SILVA et al., 2014c). Na porção central da planície costeira, a praia na APA de Maricá (Fig. 3D) mostra uma variabilidade morfológica acentuada ao longo das estações do ano em resposta às mudanças nas condições de mar. Silva et al. (2014c) constatou variações na largura de cerca de 22 metros entre as estações do ano (máxima de 88,5 metros no outono de 2012 e mínima de 66 metros no inverno de 2012). A porção central e leste do litoral, que compreende as praias da Barra de Maricá, Guaratiba, Cordeirinho e Ponta Negra, apesar da dinâmica acentuada, apresentaram largura predominando em 60-85 metros entre a primavera de 2012 e 2014, conforme Silva et al. (2015). Entretanto, este trecho do litoral preocupa devido à maior densidade de construções. Eventos de tempestades oferecem riscos a essas construções, que ocasionalmente são afetadas e até destruídas pelas ondas de maior energia (LINS-DEBARROS, 2005). Trata-se, portanto, de uma área bastante susceptível a problemas associados a eventos de tempestades. A largura do arco praial como um todo parece diminuir em direção à Ponta Negra, provavelmente devido à influência da deriva litorânea deslocando sedimentos para oeste. Em Ponta Negra (no extremo leste), um canal construído artificialmente entre rochas (Fig. 3F), conecta o mar à lagoa de Guarapina, possibilitando uma intensa troca de água e sedimentos entre esses ambientes.

Os sedimentos que compõem as praias de Maricá variam consideravelmente em tamanho e grau de selecionamento, predominando areias quartzosas grossa a média nos 34 quilômetros de costa (MUEHE, 1979; SILVA et al., 2008a; SILVA et al., 2014c; FERREIRA, 2014; SILVA et al., 2015). Em termos gerais, a granulometria apresenta diminuição de oeste para leste: areia muito grossa, com presença de cascalhos, conchas e fragmentos de arenitos predominam no extremo oeste da praia de Itaipuaçú (SILVA et al., 2008a); areia grossa a média é predominante em Itaipuaçú (exceto no extremo oeste), APA de Maricá (SILVA et al., 2014c), Barra, Guaratiba e Cordeirinho (SILVA et al., 2015); areia média representa a fração predominante em Ponta Negra, onde a 
presença de minerais pesados é marcante na faixa de areia da praia (SILVA et al., 2015).

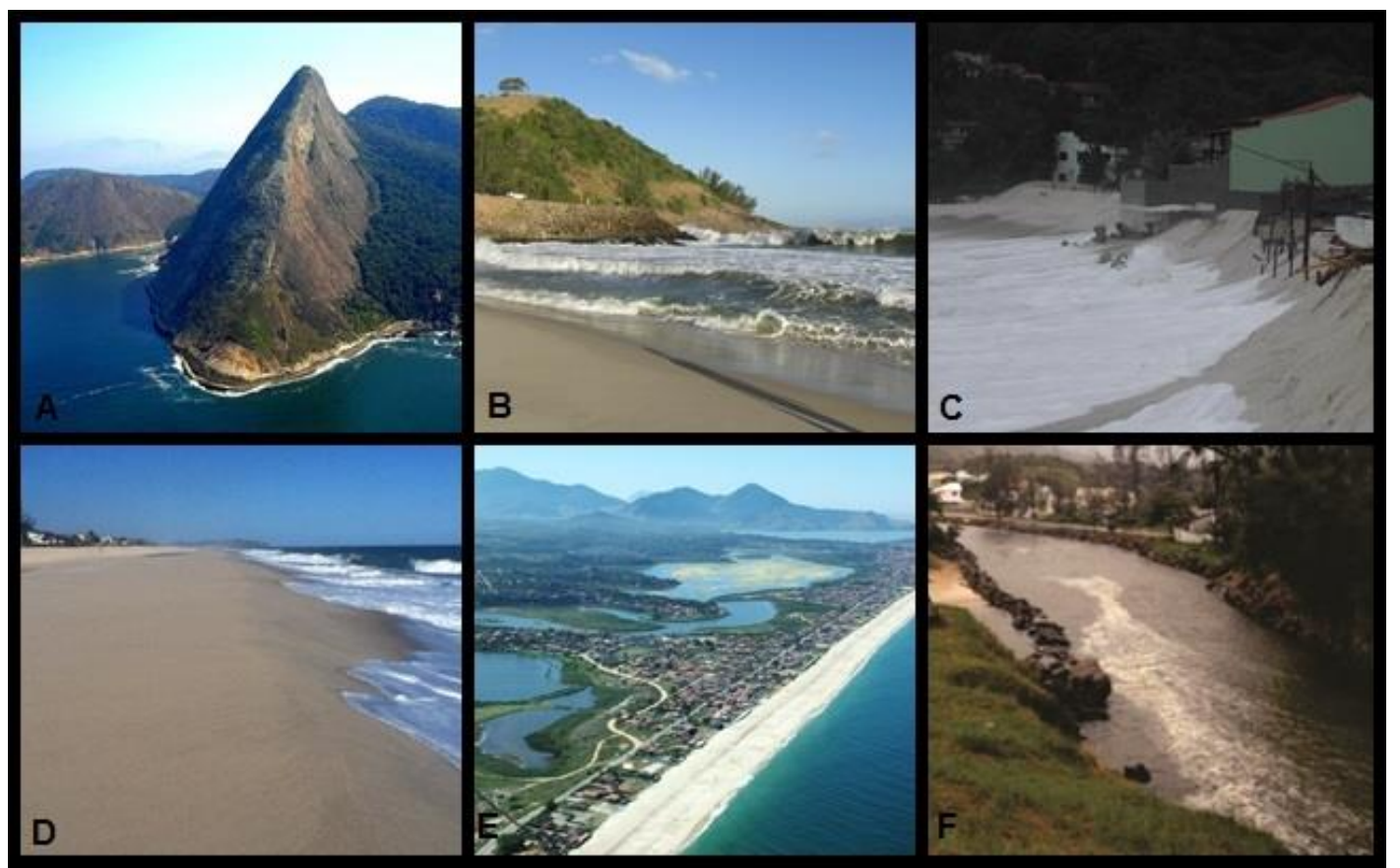

Figura 3- (A) Costão rochoso de Itaipuaçú; (B) costão rochoso de Ponta Negra; (C) extremo-oeste da praia de Itaipuaçú; (D) litoral da praia da APA de Maricá; (E) lagoas à retaguarda da barreira arenosa no litoral de Maricá; (F) canal formado artificialmente entre rochas no limite leste de Ponta Negra. Fonte: A, Paulo Xango (s/d); B, Érika Baptista (2015); C, André Silva (2004); D: Érika Baptista (2013); E, Matias Resende (s/d); F, André Silva (2012).

\section{Lagoas costeiras}

O sistema lagunar de Maricá é constituído por quatro lagoas (Maricá, Barra, Padre e Guarapina) (Fig. 1A, 1C e 3E) conectadas entre si e com o mar através do canal de Ponta Negra (Fig. 3F). Essas lagoas ocupam uma área de $37,7 \mathrm{~km}^{2}$ (SEMADS, 2001) e integram a Área de Proteção Ambiental (APA) das Lagoas criada pelo Decreto Estadual $\mathrm{n}^{\circ} 7.230$ de 23 de abril de 1984. As lagoas costeiras de Maricá são corpos d'água rasos, de baixa hidrodinâmica e de rápido preenchimento sedimentar. Estudo realizado por Oliveira et al. (1955) apontam para profundidades médias entre 1,5 e 1,7 metro para as lagoas de Maricá e Guarapina, respectivamente. Entre os principais rios que drenam para as lagoas estão o Mombuca e o (canal) da Costa na lagoa de Maricá, e o do Caranguejo em Guarapina. Esses rios contribuem para o preenchimento sedimentar dessas lagoas, que recebem também materiais remobilizados das margens e do intemperismo das rochas dentro e no entorno das lagoas. Em Itaipuaçú, o canal da Costa possui cerca de $5 \mathrm{~km}$ de extensão (Fig. 1B) e recebe esgoto sem tratamento de um 
grande número de residências. A abertura do canal de Ponta Negra diminuiu a quantidade de água nas lagoas e a urbanização de suas margens aumentou a fonte sedimentar, provocando a diminuição do espelho d'água lagunar (CRUZ et al., 1996; BARROSO et al., 2001). As margens das lagoas e áreas adjacentes (ainda não urbanizadas) preservam uma importante vegetação de restinga, com presença de cactos, bromélias e espécies de diversas gramíneas e arbustos de baixo porte, mais preservada na margem sul da lagoa de Maricá, onde se localiza a APA; e algumas áreas de floresta de Mata Atlântica, com destaque para a Ilha Cardosa.

\section{Sensibilidade ambiental do litoral de Maricá a eventos de derramamento de óleo}

Com base nas características geológicas, geomorfológicas e sedimentares do litoral de Maricá, foram estabelecidos os seguintes Índices de Sensibilidade Ambiental (Fig. 4): ISA 1, para os costões rochosos lisos; ISA 4, para as praias de areia grossa e praias intermediárias de areia fina a média, expostas à incidência de ondas oceânicas; ISA 5, para as praias mistas de areia e cascalho e conchas; e ISA 10, para as lagoas costeiras.

Os ambientes com o ISA 1 (costões rochosos lisos, de alta declividade, expostos) são caracterizados por uma exposição frequente do litoral à incidência de ondas com altura geralmente superior a 1 metro (MMA,2004). No litoral de Maricá, essas formações rochosas correspondem aos costões localizados no extremo oeste de Itaipuaçú e no limite leste de Ponta Negra (Fig. 4). Em superfícies rochosas normalmente não ocorre penetração de óleo, que tende a permanecer por pouco tempo no ambiente. A remoção do óleo no ambiente rochoso normalmente ocorre de forma rápida e natural, ainda que permaneça presente em diversas espécies de animais e vegetais marinhos (MMA, 2004).

Os ambientes litorâneos classificados com o ISA 4 (praias de areia grossa; praias intermediárias de areia fina a média, expostas) são compostos predominantemente por praias de dinâmica elevada; com sedimentos variando bastante entre areia grossa a fina, expostas à incidência direta de ondas. As áreas com ISA 4 no litoral de Maricá compreendem as praias de Itaipuaçú (exceto o extremo oeste), APA e Barra de Maricá, Guaratiba, Cordeirinho e Ponta Negra (Fig. 4), perfazendo a quase totalidade da área estudada. Em praias com essas características, a penetração do óleo na areia tende a 
ocorrer até aproximadamente $25 \mathrm{~cm}$ de profundidade; e há possibilidade de sequência de estratos com e sem contaminação, o que dificulta sua limpeza (MMA, 2004). Eventos de tempestades podem provocar a incidência de grandes ondas que são capazes de causar o estreitamento da faixa de areia da praia e, em alguns casos, a transposição dessas ondas por sobre a barreira arenosa (SILVA et al., 2008a - Fig. 5A e B) o que, no caso da presença de óleo na água e sobre a praia, poderia provocar a contaminação do sistema lagunar à retaguarda dessas barreiras no litoral de Maricá.

Os ambientes com ISA 5 (praias mistas de areia e cascalho, ou conchas e fragmentos de corais) são caracterizados por praias com dinâmica acentuada; granulometria dos sedimentos variando de areia muito grossa a grossa com presença significativa de cascalhos. A área representada pelo ISA 5 compreende o extremo oeste da praia de Itaipuaçú (Fig. 4). Nesse trecho do litoral, o deslocamento da corrente de deriva litorânea preferencialmente para oeste (SILVA et al., 2008a), tende a contribuir para a concentração de óleo e sua capacidade de percolação pode atingir profundidade superior a $50 \mathrm{~cm}$ (MMA, 2004), o que dificulta sua limpeza e favorece a ocorrência de processos erosivos.

Ambientes com ISA 10 (terraços alagadiços, banhados, brejos, margens de rios e lagoas) são representados por lagoas de substratos lamosos a arenosos; com reduzidas taxas de permeabilidade de óleo, devido à saturação deste substrato por água. As áreas abrangidas por este índice de sensibilidade compreendem as lagoas de Maricá, Barra, do Padre e de Guarapina e os canais da Costa, de Ponta Negra e os que conectam as lagoas entre si (Fig. 4). Nestes ambientes, a contaminação por um eventual derramamento de óleo pode ocorrer de forma direta, a partir do canal ligando a praia de Ponta Negra à lagoa de Guarapina (Fig. 5C); e/ou indiretamente, devido à contaminação por meio da praia durante um evento de tempestade, com ondas suficientemente capazes de transpor a barreira alcançando as áreas à retaguarda (Fig. 5A e B). A presença de óleo no sistema lagunar tende a causar sérios danos à fauna e à vegetação, colocando em risco os ecossistemas presentes nesse ambiente. A remoção deste óleo deve ocorrer de forma natural, mas é extremamente lenta devido ao baixo nível de energia e biodegradação, tendo em vista que o processo de limpeza através de maquinários é considerado impraticável pela característica lamosa de seu substrato (MMA, 2004). 


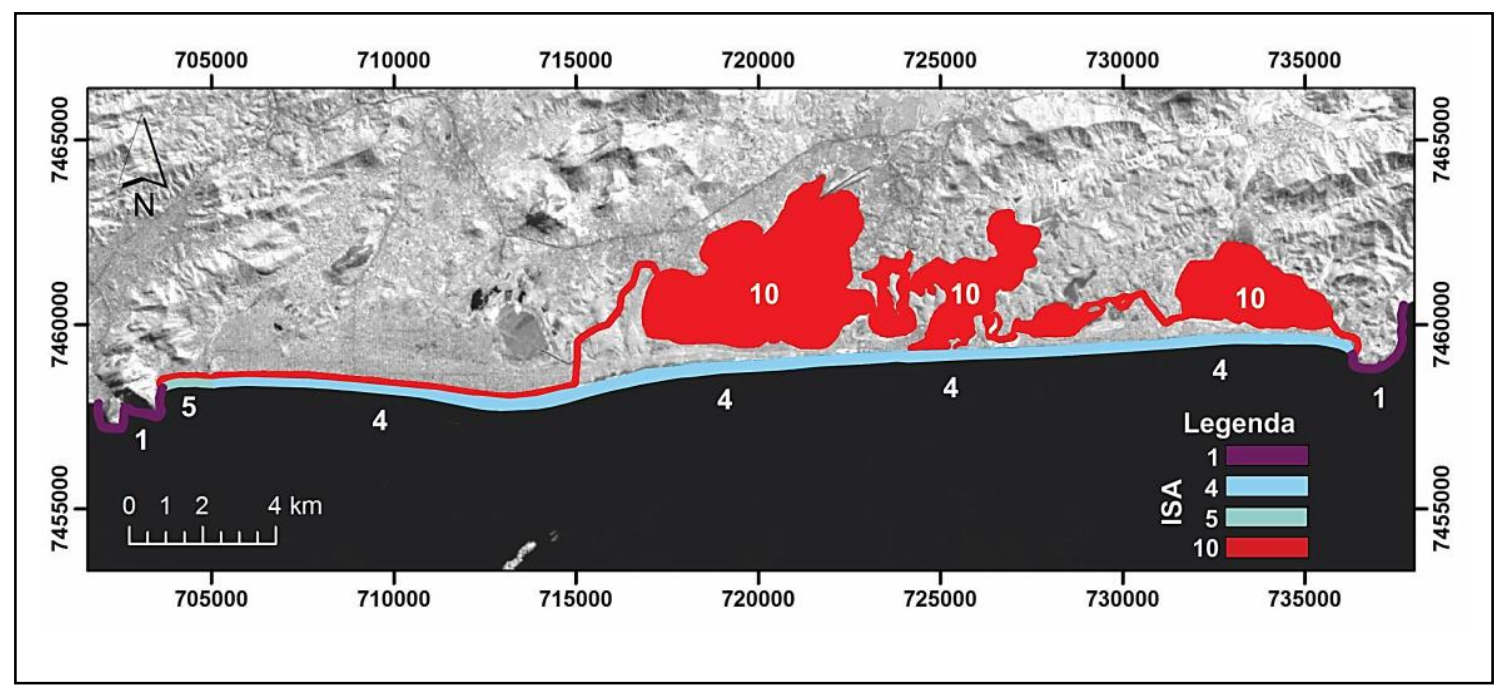

Figura 4- Mapa de Sensibilidade Ambiental para o litoral de Maricá, baseado em MMA (2004).

A análise da sensibilidade do litoral de Maricá à poluição por óleo, com base na classificação proposta pelo MMA (2004), aponta para diferentes níveis de fragilidade dos ambientes costeiros na área de estudo. A maior sensibilidade à poluição por óleo, indicada para o sistema lagunar e canais (ISA10), deve-se a menor capacidade de regeneração deste ambiente que apresenta uma baixa hidrodinâmica. A dificuldade de acesso às margens e a baixa profundidade dessas lagoas, inviabiliza a adoção de medidas de remoção de óleo com o auxílio de equipamentos, tendo em vista a impossibilidade de navegação em extensas áreas. A recuperação após um derramamento de óleo deve ocorrer de forma lenta e gradual, o que representa um impacto direto nos diversos ecossistemas costeiros e na pesca, praticada de forma artesanal por comunidades tradicionais. As praias são igualmente importantes, sobretudo para a população de Maricá, por se tratar de ambientes em que ocorrem atividades de lazer, comércio ao longo da orla e a pesca. A grande variabilidade nas condições de mar e a ocorrência eventual das ressacas, tão comuns neste litoral (MUEHE, 1979; SILVA et al., 2008a; SILVA et al., 2008b GRALATO, 2013; SILVA et al., 2014c; FERREIRA, 2014; SILVA et al., 2015), tende a alterar de forma significativa o alcance e a intensidade dos impactos causados por um eventual desastre com derramamento de óleo. Mudanças acentuadas na largura e morfologia da praia em toda a extensão do litoral (SILVA et al., 2008a; SILVA et al., 2014c; FERREIRA, 2014; SILVA et al., 2015), tende a contribuir para o aumento da profundidade de infiltração do óleo nos sedimentos e na dispersão deste devido a ação das correntes, tanto ao longo da praia 
$\overline{\text { (deriva litorânea), quanto entre a porção emersa e submersa da mesma (corrente de }}$ retorno). Estudos realizados por diversos autores (BOULHOSA \& SOUZA FILHO, 2009; CASTRO et al., 2003; FINGAS, 2000; MENEGHETTI et al., 2011; ROCHA, 2009; ROMERO, 2009) chamam a atenção para a necessidade da adoção de medidas adequadas à fragilidade de cada ambiente e para a identificação de ações e áreas prioritárias para proteger a costa da poluição por óleo e, consequentemente, de danos aos ecossistemas costeiros e marinhos, assim como, as inúmeras atividades nela desenvolvidas.

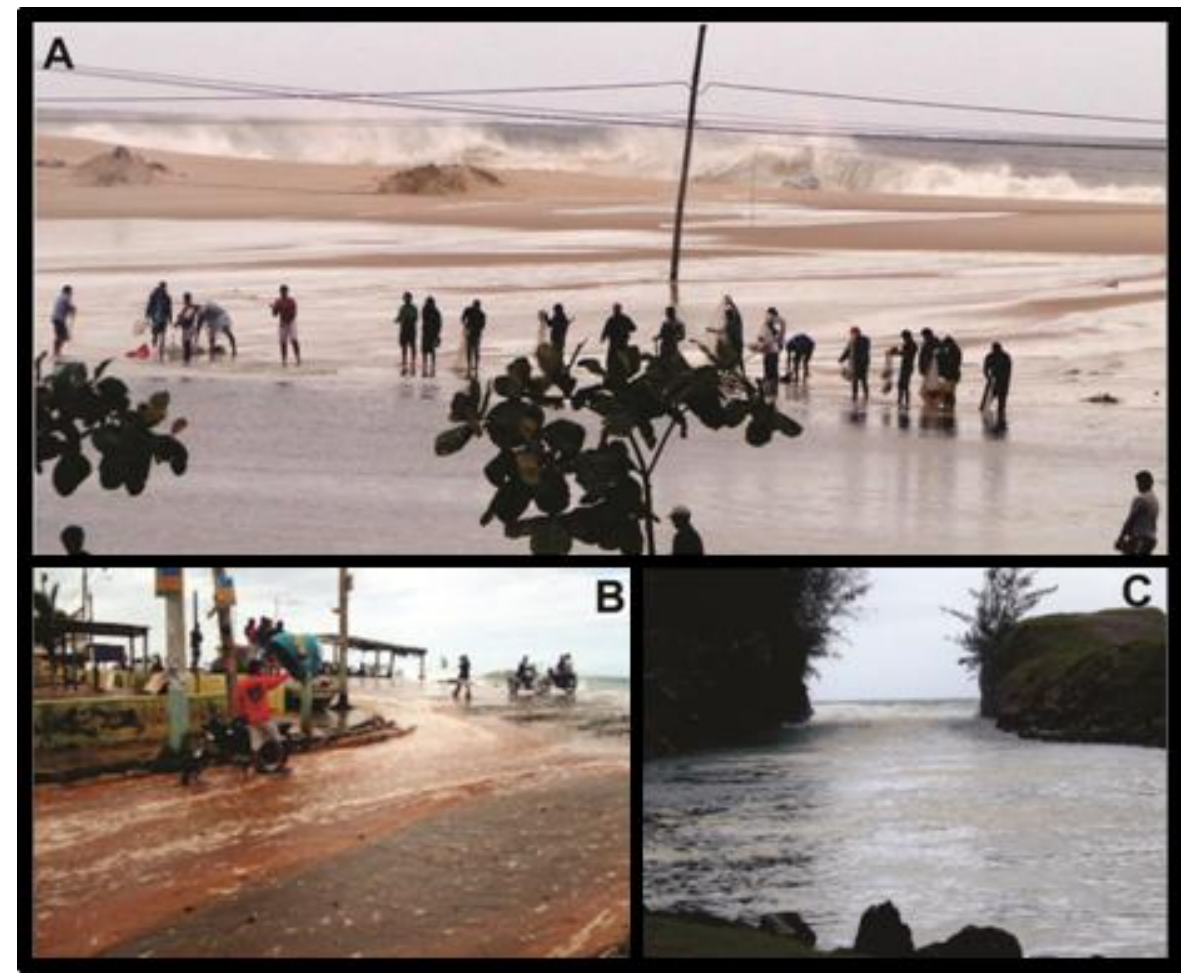

Figura 5 - Transposição de ondas de tempestades por sobre a barreira arenosa no litoral de Maricá: na praia da Barra de Maricá (A) e em Itaipuaçú (B); canal de Ponta Negra que liga a laguna de Guarapina ao oceano (C). A: autor desconhecido; B: Marcelo Alecrim, 2011; C: André Silva (2012).

\section{CONCLUSÕES}

A partir das principais características geomorfológicas da área estudada foi realizada uma classificação do litoral de Maricá quanto ao Índice de Sensibilidade Ambiental a eventos de derramamentos de óleo. Esse litoral, desde Itaipuaçú até Ponta Negra, apresenta quatro índices distintos quanto à sensibilidade à poluição por óleo. Os índices encontrados atingem os dois extremos dessa classificação, variando de 1 a 10, 
perpassando pelos níveis intermediários de 4 e 5 . Tal fato decorre da grande variedade de elementos na paisagem costeira de Maricá.

O estudo da sensibilidade ambiental do litoral de Maricá associado a derramamento de óleo aponta para a fragilidade deste trecho do litoral fluminense a um desastre dessa natureza, o que tende a causar sérios danos às atividades pesqueiras, destruir a biodiversidade da restinga e do sistema lagunar, comprometer os diversos ecossistemas costeiros e marinhos, entre outros. Trata-se, portanto, de um litoral cada vez mais vulnerável às modificações e interferências antrópicas dentro desses ambientes. Desta forma, faz-se necessária a ampliação de análises de risco quanto aos impactos em áreas que podem ser diretamente afetadas pela poluição por óleo e cujas atividades econômicas e industriais podem comprometer o equilíbrio dos diversos ecossistemas costeiros em Maricá.

\section{Agradecimentos}

Agradecemos ao professor Vinicius Seabra pelo suporte técnico na confecção do mapa de sensibilidade ambiental. Nossos sinceros agradecimentos aos estudantes que participaram da aquisição de dados ao longo do litoral de Maricá.

\section{REFERÊNCIAS BIBLIOGRÁFICAS}

BARROSO, L. V.; ABDO, O. E.; XAVIER-DA-SILVA, J. 2001. Geoprocessamento aplicado aos sistemas lagunares de Niterói, Maricá e Saquarema, Região Costeira Leste-Fluminense (RJ). Anais X Simpósio Brasileiro de Sensoriamento Remoto, Foz do Iguaçu, Brasil, 21-26 abril 2001, INPE, pp. 915-919.

BOUlhOSA, M. B. M.; SOUZA FILHO, P. W. M. 2009. Reconhecimento $e$ mapeamento dos ambientes costeiros para geração de mapas de ISA ao derramamento de óleo, Amazônia Oriental. Revista Brasileira de Geofísica. pp. 23-37.

CASTRO, A. F.; SOUTO, M. V. S.; AMARO, V. E.; VITAL, H. 2003. Desenvolvimento e aplicação de um banco de dados geográficos na elaboração de mapas da morfodinâmica costeira e sensibilidade ambiental ao derramamento de óleo em áreas costeiras localizadas no Estado do Rio Grande do Norte. Revista Brasileira de Geociências. V. 33, pp. 53 - 64. 
CRUZ, C. B. M.; CARVALHO JÚNIOR, W. DE; BARROS, R. S. DE; ARGENTO, M.

S. F.; MAYR, L. M. 1996. Impactos ambientais no sistema lagunar de MaricáGuarapina. Anais VIII Simpósio Brasileiro de Sensoriamento Remoto, Salvador, Brasil, 14-19 abril 1996, INPE, pp. 137-141.

DHN, Folha de Bordo, FB - 1500-001/79. Diretoria de Hidrografia e Navegação da Marinha do Brasil, 1980.

DRM, RJ. Departamento de Recursos Minerais do Estado do Rio de Janeiro. Mapa Geológico do Estado do Rio de Janeiro. Escala 1:400.000, 1977.

FARIA, C. P. \& BOHRER, C. B. A. 2005. As Unidades de Paisagem da APA Estadual de Maricá/RJ. Anais do XI Simpósio Brasileiro de Geografia Física Aplicada, USP, pp. 2.947-2.953.

FERREIRA, J. R. 2014. Avaliação do estágio morfodinâmico das praias de Maricá, RJ. Monografia do curso de graduação em Geografia da UERJ-FFP. pp. 63.

FINGAS, M. 2000. The basics of oil spill cleanup. Ed. Lewis Publishers, Washington D.C. pp. 11-39.

GRALATO, J. C. A. 2013. Variabilidade sazonal da praia na APA de Maricá - RJ. Monografia apresentada ao Curso de Licenciatura Plena em Geografia da Faculdade de Formação de Professores da Universidade do Estado do Rio de Janeiro.

LINS-DE-BARROS, F. M. 2005. Risco, Vulnerabilidade Física à Erosão Costeira e Impactos Sócio-econômicos na Orla Urbanizada do Município de Maricá, Rio de Janeiro. Revista Brasileira de Geomorfologia - Ano 6, nº 2, pp. 83-90.

LOUREIRO, D. S., MATIAS, M. L. \& FREIRE, D. G. 2010. Avaliação do conflito socioambiental na APA da restinga de Maricá-RJ. XVI Encontro Nacional dos Geógrafos. Porto Alegre, pp. 10.

MENEGHETTI, G. T.; RIEDEL, P. S.; STURARO, J. R. 2011. Caracterização da sensibilidade ambiental ao óleo - litoral sul paulista com o apoio de técnicas de Geoprocessamento. Anais XV Simpósio Brasileiro de Sensoriamento Remoto. pp. 4979 - 4985.

MINISTÉRIO DO MEIO AMBIENTE. 2004. Especificações e normas técnicas para elaboração de cartas de sensibilidade ambiental para derramamentos de óleo. 
MUEHE, D. C. E. H. 1979. Sedimentology and Topography of a High Energy Coastal Environment between Rio de Janeiro and Cabo Frio - Brazil. Anais da Academia Brasileira de Ciências. 51 (3), pp. 473-481.

OLIVEIRA, L.; NASCIMENTO, R. KRAU, L. \& MIRANDA, A. 1955. Observações biogeográficas e hidrobiológicas sobre a lagoa de Maricá. Memórias do Instituto Oswaldo Cruz, 53. p. $171-227$.

ROCHA, T. C. F. 2009. Mapeamento da sensibilidade ambiental do litoral de Ubatuba - SP a vazamentos de petróleo. Dissertação de mestrado apresentada ao Programa de Pós-graduação em Geociências e Meio Ambiente da Universidade Estadual Paulista.

ROMERO, A. F. 2009. Mapa de vulnerabilidade ambiental ao óleo e cartas SAO. Trecho: Praia Grande - Ilha Comprida, litoral paulista. Tese de doutorado apresentada ao Programa de Pós-graduação em Geociências e Meio Ambiente da Universidade Estadual Paulista.

\section{SECRETARIA DE ESTADO DE MEIO AMBIENTE E DESENVOLVIMENTO} SUSTENTÁVEL - SEMADS. 2001. Bacias Hidrográficas e Rios Fluminenses Síntese Informativa por Macrorregião Ambiental. Rio de Janeiro: SEMADS 2001.

SILVA, A. L. C. 2006. Comportamento Morfológico e Sedimentológico do Litoral de Itaipuaçú (Maricá) e Piratininga (Niterói), RJ, nas últimas três décadas. Dissertação de Mestrado, Programa de Pós Graduação em Geologia e Geofísica Marinha da Universidade Federal Fluminense, pp.153.

SILVA, A. L. C.; SILVA, M. A. M.; SANTOS, C. L. 2008a. Comportamento morfológico e sedimentar da praia de Itaipuaçú (Maricá, RJ) nas últimas três décadas. Revista Brasileira de Geociências. V.38 (1), pp. 89-99

SILVA, A. L. C.; SILVA, M. A. M.; SANTOS, C. L.; RIBEIRO, G. B.; SANTOS, R. A.; VASCONCELOS, S. C. 2008b. Retrogradação da Barreira Arenosa e Formação de Leques de Arrombamento na Praia de Itaipuaçú (Oeste de Maricá, $R J)$ ”. Revista Brasileira de Geomorfologia. Ano 9, n.2, pp. 75-82.

SILVA, A. L. C. 2011. Arquitetura sedimentar e Evolução Geológica da planície costeira central de Maricá (RJ) ao longo do Quaternário. Tese de Doutorado apresentada ao programa de Pós-Graduação em Geologia e Geofísica Marinha da Universidade Federal Fluminense, Niterói, RJ. pp.153. 
SILVA, A. L. C., SILVA, M. A. M., SOUZA, R. S., VILELA PINTO, M. L. 2014a. The role of beachrocks on the evolution of the Holocene Barrier System in Rio de Janeiro, Southeasten Brazil. Journal of Coastal Research, Special Issue No. 70, 170-175.

SIlvA, A. L. C.; SIlvA, M. A. M.; GAMBOA, L. A. P. \& RODRIGUES, A. R. 2014b. Sedimentary architecture and depositional evolution of the Quaternary coastal plain of Maricá, Rio de Janeiro, Brazil. Brazilian Journal of Geology, Vol. 44, n² 2, p. 191-206.

SILVA, A. L. C.; SILVA, M. A. M.; GRALATO, J. C. A.; SILVESTRE, C. P. 2014c. Caracterização geomorfológica e sedimentar da planície costeira de Maricá (Rio de Janeiro). Revista Brasileira de Geomorfologia. V.15, n.2, pp. 231-249.

SILVA, T. S.; SILVA, A. L. C.; PINTO, V. C. S.; PINHEIRO, A. B. 2015. Morfologia e sedimentologia das praias da Barra de Maricá, Guaratiba, Cordeirinho e Ponta Negra no litoral oriental de Maricá, RJ. XVI Simpósio Brasileiro de Geografia Física Aplicada. Teresina, pp. 1728-1734.

SKINNER, B. J.; TUREKIAN, K. K. 1977. O homem e o oceano. Ed. Universidade de São Paulo. pp. 118 - 136.

http://oglobo.globo.com/economia/petrobras-estuda-gasoduto-da-bacia-de-santos-atepraia-em-marica-8066565 Acessado em: 04/08/2013.

http://noticias.uol.com.br/ciencia/album/100430vazamentos_album.htm\#fotoNav=2 . Acessado em: 04/08/2013.

http://g1.globo.com/sp/vale-do-paraiba-regiao/noticia/2013/04/cetesb-avalia-danosambientais-apos-vazamento-de-oleo-em-sao-sebastiao.html. Acessado em: 04/08/2013.

http://noticias.r7.com/cidades/noticias/apos-vazamento-de-oleo-limpeza-de-praia-detramandai-e-concluida-diz-transpetro-20120127.html. Acessado em: 22/09/2013.

http://meioambiente.culturamix.com/ecologia/maiores-vazamentos-de-petroleo-domundo. Acessado em: 22/09/2013.

http://noticias.band.uol.com.br/cidades/rio/noticia/100000757576/Derramamento-deoleo-atinge-Rio-Itingucu-e-Baia-de-Sepetiba.html Acessado em: 05/10/2015.

http://www.oeco.org.br/reportagens/28021-baia-de-guanabara-vazamento-da-petrobrascompleta-14-anos/ Acessado em: 05/10/2015.

http://economia.estadao.com.br/noticias/geral,petrobras-pagara-r-610-mi-porvazamento-no-parana,1064446 Acessado em: 05/10/2015. 
http://noticias.ambientebrasil.com.br/clipping/2005/11/15/21716-explosao-do-naviovicua-no-porto-de-paranaguapr-ainda-sem-culpados.html Acessado em: 05/10/2015.

http://g1.globo.com/sp/vale-do-paraiba-regiao/noticia/2012/09/secretario-fala-sobrevazamento-de-oleo-diesel-em-sao-sebastiao.html Acessado em: 05/10/2015.

http://exame.abril.com.br/mundo/noticias/10-maiores-acidentes-petroliferos-historia556774 Acessado em: 05/10/2015. 